\title{
Genetic markers associated with insecticide resistance and resting behaviour in Anopheles gambiae mosquitoes in selected sites in Kenya
}

Sharon Mwagira-Maina ${ }^{*} \mathbb{E}$, Steven Runo ${ }^{1}$, Lucy Wachira², Stanley Kitur², Sarah Nyasende ${ }^{3}$, Brigid Kemei ${ }^{4}$, Eric Ochomo ${ }^{4}$, Damaris Matoke-Muhia ${ }^{2}$, Charles Mbogo ${ }^{5}$ and Luna Kamau ${ }^{2}$

\begin{abstract}
Background: Molecular diagnostic tools have been incorporated in insecticide resistance monitoring programmes to identify underlying genetic basis of resistance and develop early warning systems of vector control failure. Identifying genetic markers of insecticide resistance is crucial in enhancing the ability to mitigate potential effects of resistance. The knockdown resistance $(k d r)$ mutation associated with resistance to DDT and pyrethroids, the acetylcholinesterase-1 $\left(\right.$ ace $\left.-1^{R}\right)$ mutation associated with resistance to organophosphates and carbamates and 2La chromosomal inversion associated with indoor resting behaviour, were investigated in the present study.

Methods: Anopheles mosquitoes sampled from different sites in Kenya and collected within the context of malaria vector surveillance were analysed. Mosquitoes were collected indoors using light traps, pyrethrum spray and hand catches between August 2016 and November 2017. Mosquitoes were identified using morphological keys and Anopheles gambiae sensu lato (s.l.) mosquitoes further identified into sibling species by the polymerase chain reaction method following DNA extraction by alcohol precipitation. Anopheles gambiae and Anopheles arabiensis were analysed for the presence of the $k d r$ and $a c e-7^{R}$ mutations, while 2 La inversion was only screened for in An. gambiae where it is polymorphic. Chi-square statistics were used to determine correlation between the 2La inversion karyotype and kdr-east mutation.
\end{abstract}

Results: The kdr-east mutation occurred at frequencies ranging from 0.5 to $65.6 \%$ between sites. The $k d r$-west mutation was only found in Migori at a total frequency of $5.3 \%(n=124)$. No $k d r$ mutants were detected in Tana River. The ace- $7^{R}$ mutation was absent in all populations. The 2 La chromosomal inversion screened in An. gambiae occurred at frequencies of $87 \%(n=30), 80 \%(n=10)$ and $52 \%(n=50)$ in Baringo, Tana River and Migori, respectively. A significant association between the 2 La chromosomal inversion and the $k d r$-east mutation was found.

Conclusion: The significant association between the 2 La inversion karyotype and kdr-east mutation suggests that pyrethroid resistant An. gambiae continue to rest indoors regardless of the presence of treated bed nets and residual sprays, a persistence further substantiated by studies documenting continued mosquito abundance indoors. Behavioural resistance by which Anopheles vectors prefer not to rest indoors may, therefore, not be a factor of concern in this study's malaria vector populations.

Keywords: Insecticide resistance, $K d r$ mutation, Ace- $1^{R}$ mutation, 2 La inversion

*Correspondence: Mwagira3@gmail.com

1 Department of Biochemistry and Biotechnology, Kenyatta University, P.O Box 43844-00100, Nairobi, Kenya

Full list of author information is available at the end of the article original author(s) and the source, provide a link to the Creative Commons licence, and indicate if changes were made. The images or other third party material in this article are included in the article's Creative Commons licence, unless indicated otherwise in a credit line to the material. If material is not included in the article's Creative Commons licence and your intended use is not permitted by statutory regulation or exceeds the permitted use, you will need to obtain permission directly from the copyright holder. To view a copy of this licence, visit http://creativecommons.org/licenses/by/4.0/. The Creative Commons Public Domain Dedication waiver (http://creativecommons.org/publicdomain/zero/1.0/) applies to the data made available in this article, unless otherwise stated in a credit line to the data. 


\section{Background}

Malaria is one of the most prevalent vector-borne diseases in sub-Saharan Africa. According to the 2020 World Malaria Report, about 384,000 people in this region succumbed to the disease in the year 2019, most of them being children aged five years and below, and expectant mothers. Kenya accounted for $1 \%$ of deaths due to malaria globally [1]. Efforts towards malaria elimination in Kenya are focused on vector control and case management. The primary tools for malaria vector control in the country are Indoor Residual Spraying (IRS) and Long-Lasting Insecticidal Nets (LLINs). These interventions have been in use in the country for over twenty years, but their scaled-up utilization was only initiated in the 2000s. Insecticide-treated nets (ITNs) are distributed through ante-natal and child welfare clinics, comprehensive care clinics, designated rural shops, retail outlets and mass campaigns [2]. Kenya, being one among the countries most affected by the disease is listed under the US Government's President's Malaria Initiative (PMI) as a focus country for IRS- with the aim of limiting exposure to malaria vectors and reducing disease incidence and prevalence [3]. A number of studies show that the combined use of IRS and LLINs have led to a significant reduction in malaria morbidity and mortality in the country $[4,5]$. However, these gains could be watered down by shifts in vector behaviour and the development of resistance to insecticides by the Anopheles mosquito vectors of malaria, coupled with resistance to anti-malarial drugs by Plasmodium parasites that cause the disease.

Genetic markers have been used for characterization of the molecular basis of insecticide resistance. Knockdown resistance $(k d r)$ and acetylcholinesterase-1 $\left(\right.$ ace- $\left.1^{R}\right)$ are single nucleotide polymorphic-type and restriction fragment length polymorphic-type biochemical markers, respectively, which detect changes in the amino acid sequence that brings about refractoriness to specific insecticides. $K d r$ for instance, confers resistance to pyrethroid and DDT insecticides, and is usually as a result of either a serine or a phenylalanine amino acid substituting a Leucine amino acid at locus 1014 of the voltage gated sodium channel gene $(\mathrm{Vgsc})$ resulting in either an L1014S (Vgsc-1014S) or L1014F (Vgsc-1014F) mutation [6]. The ace-1 ${ }^{\mathrm{R}}$ mutation causes resistance to carbamates and organophosphates and results from a point mutation at locus 119 where guanine is replaced with serine amino acid hence denoted as the G119S mutation [7]. The 2La inversion, denoted as $2 \mathrm{La} / 2 \mathrm{La}$, is one of the alternative arrangements of genes on the left arm of chromosome 2 and is a molecular marker associated with adaptation to different microclimates, desiccation resistance and mosquito behaviours [8]. Other arrangements include the standard arrangement and the heterokaryotype arrangement denoted as $2 \mathrm{~L}+{ }^{\mathrm{a}} / 2 \mathrm{~L}+{ }^{\mathrm{a}}$ and $2 \mathrm{La} / 2 \mathrm{~L}+{ }^{\mathrm{a}}$, respectively. While Anopheles arabiensis is fixed for this inversion karyotype, Anopheles gambiae remains highly polymorphic for the inversion. Since the different karyotypes are associated with different ecological conditions, the polymorphic An. gambiae has the advantage of ecological plasticity and this explains why it is widespread in Africa [9]. Genetic markers of insecticide resistance provide early warning of possible control failure in the future thereby enhancing the ability to cushion the possible negative effects of resistance on malaria vector control.

Resistance to various insecticides has been reported from multiple sites in Kenya [10]. It is likely that malaria incidence and mortality could substantially increase if insecticide resistance is left unchecked. Already, a rise in malaria prevalence has been reported at the Kenyan Coast even with the current malaria control strategies in place [11]. Indeed, insecticide resistance is one of the contributing factors towards the rise of malaria in areas where malaria prevalence had previously declined [12]. It is for this reason that the World Health Organization (WHO) through the Global Plan for Insecticide Resistance Management (GPIRM) calls upon the global malaria community to take urgent action to prevent an increase in insecticide resistance with the goal of ensuring that available vector control interventions remain effective. Insecticide resistance surveillance and management of any emerging resistance is a key strategy within this plan [13]. Understanding insecticide resistance mechanisms is vital for the rational management of insecticide resistance as it allows informed choice of replacement insecticides and their effective deployment [14]. In this study, we analysed An. arabiensis and An. gambiae mosquitoes sampled from selected sites in Kenya for the presence of two mutations associated with insecticide resistance. The first was the G119S (Glycine to Serine amino acid) mutation in the Acetylcholinesterase 1 (AChE-1) gene that is associated with resistance to organophosphate and carbamate insecticides [15]. The second was the L1014S or L1014F (Leucine to Serine or Leucine to Phenylalanine substitution) mutation at position 1014 of the voltage-gated sodium channel gene, that is associated with resistance to pyrethroids and organochlorines [16]. In addition, An. gambiae mosquitoes were analysed for the presence of the 2La chromosomal inversion that has been shown to be associated with an increased propensity for resting indoors at night where a saturation deficit exists [17]. This was so as to gain insights on behavioural adaptations that may impact the effectiveness of vector control interventions. 


\section{Methods}

\section{Study area}

The study was conducted in four sites in Kenya (Fig. 1) which are representative of different malaria epidemiological zones in the country. These were: Migori in the lake endemic region, Baringo in the highland epidemic region, Kirinyaga in the low risk malaria transmission zone and Tana River located in the seasonal transmission zone. The sites also vary in terms of vector species composition. Kirinyaga county has An. arabiensis as its predominant vector species with rare occurrence of $A n$. gambiae, while Migori, Baringo and Tana River counties have these two target species coexisting.

\section{Mosquito specimens}

Archived Anopheles gambiae sensu lato (s.l.) mosquitoes collected indoors using light traps and manual aspiration, between August 2016 and November 2017 within the context of a malaria vector survey conducted by Kenya Medical Research Institute (KEMRI) and the Kenya National Malaria Control Programme (NMCP) were used in this study. Light traps were set up inside selected houses at the foot side of the bed $1 \mathrm{~m}$ off the ground and were collected the following morning between 0600 and $0700 \mathrm{~h}$. Indoor resting mosquitoes were collected using mouth aspirators between 0700 and $0900 \mathrm{~h}$.

\section{Sample processing and identification}

Anopheles gambiae (s.l.) mosquitoes were identified based on morphology [18] and were dissected into abdomen, legs, wings, head and thorax. Blood-fed abdomens, heads and thoraces were stored separately for other analysis. Genomic DNA was extracted from the legs, wings and unfed abdomens following the protocol of Collins et al. [19]. A portion of the extracted DNA was utilized in identification of An. gambiae and An. arabiensis sibling species, the two most predominant species in Kenya, using the polymerase chain reaction (PCR) assay [20].

\section{Genotyping of the $k d r$ and of $a c e-1^{R}$ mutations}

The $k d r$ mutations in An. gambiae and An. arabiensis were analysed using real-time quantitative polymerase chain reaction (qPCR). A modified version of the protocol by Ochomo et al. [6] was followed. Real time-PCR

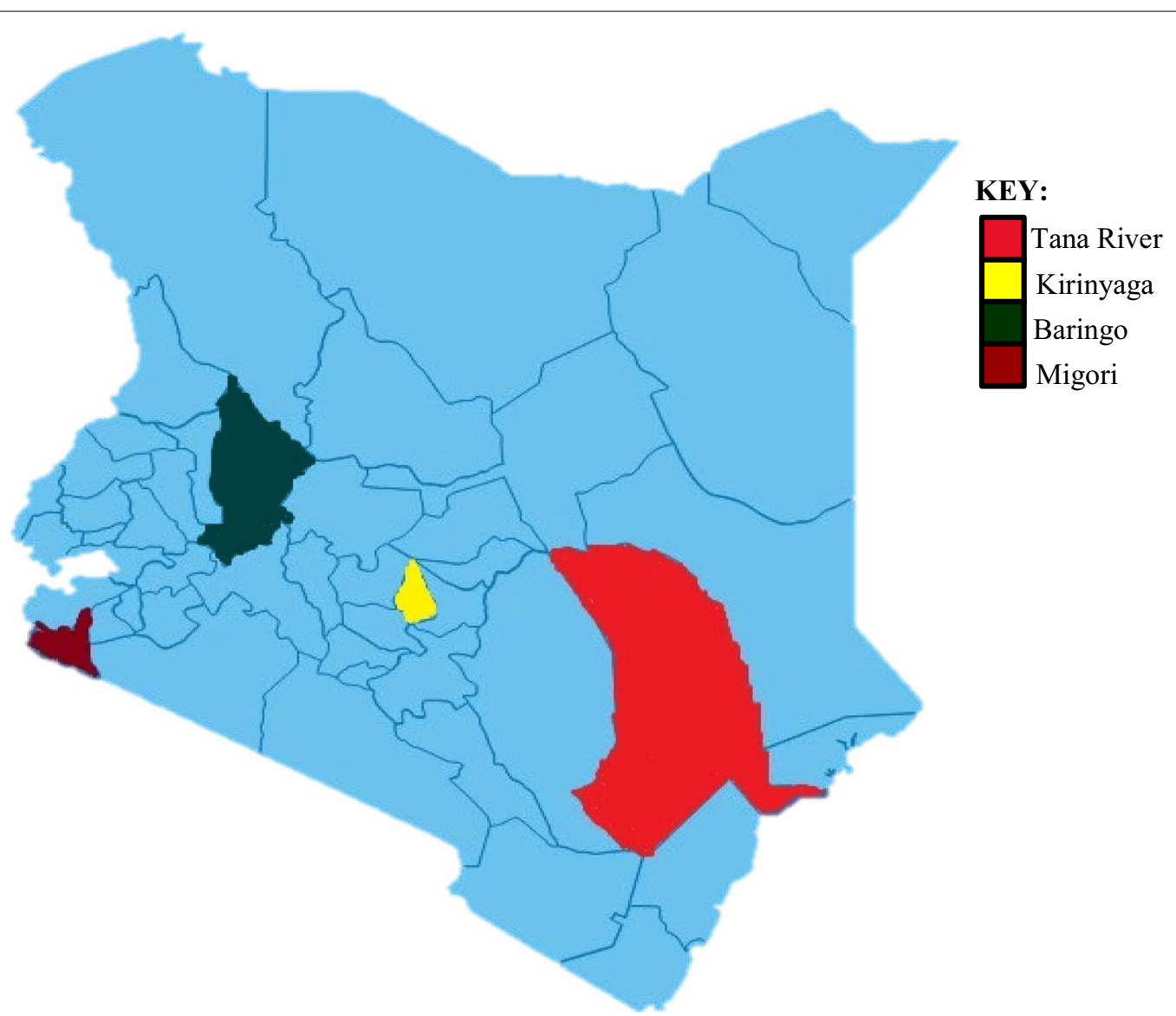

Fig. 1 A Kenyan map showing Migori, Baringo, Kirinyaga and Tana River counties 
reactions were run using a 96-well format on a Strata gene MxPro 3000 machine. Reaction curves for each set of reactions were visualized using Stratagene Mx3000P QPCR software and genotypes scored by eye. To detect the G119S mutation, a PCR-Restriction Fragment Length Polymorphism (RFLP) assay was conducted as described by Weill et al. [7]. The activity of the Alu I enzyme that was used in the restriction digest of amplified PCR-fragments was confirmed by restriction of Lambda DNA to expected fragments.

\section{Molecular karyotyping of the 2La chromosomal inversion}

Presence of $2 \mathrm{La}$ chromosomal inversion was determined by the PCR assay of White and others as previously described [21].

\section{Data analysis}

Data was analysed using STATA version 14.2 and Microsoft Excel version 10. Allele frequencies were generated for each molecular marker in the study sites using Microsoft Excel. The chi-square test was applied to determine whether allele frequencies varied significantly across different populations. Inversion genotypes and $k d r$ genotypes were tested for their conformation to Hardy Weinberg equilibrium. Chi-square tests were used to determine association between the 2La inversion and the $k d r$-east mutation.

\section{Results}

Distribution of An. gambiae and An. arabiensis sibling species

A total of 731 An. gambiae (s.l.) mosquitoes were tested, with 666 specimens (representing 91.1\%) successfully amplifying. Of the 666 specimens that were successfully amplified, 90.5\% $(\mathrm{n}=603)$ were identified as $A n$. arabiensis and 9.5\% $(\mathrm{n}=63)$ as An. gambiae. Sixty-five specimens (representing $8.9 \%$ ) of the total number of specimens tested failed to amplify. Both An. arabiensis and An. gambiae were found to occur in sympatry in the study sites at frequencies of $86.5 \%(n=96)$ versus $13.5 \%(n=15)$ in Baringo, $72 \%(n=103)$ versus $28 \%(n=40)$ in Migori and $95.2 \%(n=157)$ versus $4.8 \%(n=8)$ in Tana River, respectively. In Kirinyaga, only $A n$. arabiensis was found. Table 1 is a summary of the An. gambiae (s.l.) sibling species distribution.

\section{Distribution of the vgsc-1014S and $v g s c-1014 \mathrm{~F} k d r$ alleles} A total of 308 samples were analysed for the $k d r$ mutation. Table 2 summarizes the frequencies of $k d r$ alleles in individual sibling species across the four study sites. The vgsc-1014S mutation occurred in both heterozygous and homozygous state with allele distributions conforming to Hardy-Weinberg expectations in all cases. The frequency
Table 1 Distribution of An. gambiae and An. arabiensis across study sites

\begin{tabular}{llll}
\hline Study site & N & $\begin{array}{l}\text { An.arabiensis } \\
\text { proportions (\%) }\end{array}$ & $\begin{array}{l}\text { An. gambiae } \\
\text { proportions } \\
\text { (\%) }\end{array}$ \\
\hline Baringo & 111 & 86.5 & 13.5 \\
Migori & 143 & 72 & 28 \\
Tana River & 165 & 95 & 4.8 \\
Kirinyaga & 247 & 100 & - \\
Mean & 166.5 & 88.4 & 11.6 \\
\hline
\end{tabular}

of $v g s c-1014 S$ allele varied between species and across the different sites. Anopheles gambiae recorded a frequency of $65.6 \%(n=32)$ and $9.4 \%(n=32)$ in Migori and Baringo counties, respectively. Low frequencies $(1.9 \%(\mathrm{n}=160)$ in Baringo and $0.5 \%(\mathrm{n}=196)$ in Kirinyaga) of the allele were observed in An. arabiensis. Tana River County had no record of the $v g s c-1014 S$ allele. The $v g s c-1014 \mathrm{~F}$ mutation was only recorded in Migori County in heterozygous state at a total frequency of $5.3 \%(n=124)$. The distribution of the vgsc-1014F allele also varied between species with An. gambiae sensu stricto (s.s.) and An. arabiensis recording frequencies of $2.2 \%(\mathrm{n}=32)$ and $3.1 \%(\mathrm{n}=92)$, respectively.

\section{Distribution of the G119S mutation}

The substrate DNA lambda used to test the activity of Alu I enzyme was successfully digested into multiple fragments, confirming the activity of the enzyme. PCR amplification of the expected 194 bp fragment was successful in 60 An. gambiae and 140 An. arabiensis specimens, respectively. However, none of the resulting PCR amplicons were digested by the $A l u$ I enzyme, indicating absence of the G119S allele in all the study populations.

\section{Distribution of the 2La chromosomal inversion}

Out of the $63 A n$. gambiae mosquitoes tested for the presence of the $2 \mathrm{La}$ chromosomal inversion, 45 successfully amplified. The $2 \mathrm{La}$ inversion allele occurred both in homozygous and heterozygous states and at allele frequencies of $87 \%(n=30), 80 \%(n=10)$ and $52 \%$ $(\mathrm{n}=50)$ in Baringo, Tana River and Migori, respectively (Table 3). Compared to the heterokaryotype which was only found in Migori at $8 \%(n=2)$, the homokaryotype inversion arrangement was more frequent and appeared at frequencies of $87 \%(n=13)$ in Baringo, $80 \%(n=4)$ in Tana River and $48 \%(\mathrm{n}=12)$ in Migori. As expected, the 50 (100\%) An. arabiensis that were randomly selected for screening were found to be fixed for the $2 \mathrm{La}$ inversion homokaryotype. 
Table 2 Frequencies of $k d r$ alleles in An. arabiensis and An. gambiae in the four study sites

\begin{tabular}{llllllll}
\hline Study site & \multicolumn{2}{l}{ An. arabiensis } & & & \multicolumn{2}{l}{ An. gambiae } \\
\cline { 2 - 4 } & N & L1014S (\%) & L1014F (\%) & & N & L1014S (\%) & L1014F (\%) \\
\hline Migori & 92 & - & 3.1 & - & 32 & 65.6 & 2.2 \\
Baringo & 160 & 1.9 & - & -32 & - & - \\
Kirinyaga & 196 & 0.5 & - & - & 10 & - & - \\
Tana River & 94 & & &
\end{tabular}

L1014S: Leucine to Serine heterozygous $k d r$ mutant

L1014F: Leucine to Phenylalanine heterozygous kdr mutant

Table 3 Distribution of allele and karyotype frequencies of the 2La inversion in An. gambiae

\begin{tabular}{|c|c|c|c|c|c|}
\hline Site & $\begin{array}{l}\text { No. specimens } \\
\text { (n) }\end{array}$ & $\begin{array}{l}\text { No. } \& \% \text { of standard } \\
\text { karyotype } \\
2 \mathrm{~L}+{ }^{\mathrm{a}} / 2 \mathrm{~L}++^{\mathrm{a}}\end{array}$ & $\begin{array}{l}\text { No. \& } \% \text { of inversion } \\
\text { Heterokaryotype } \\
2 \mathrm{La} / 2 \mathrm{~L}+{ }^{\mathrm{a}}\end{array}$ & $\begin{array}{l}\text { No. \& \% of inversion } \\
\text { homokaryotype } \\
\text { 2La/2La }\end{array}$ & $\begin{array}{l}\% 2 \mathrm{La} \\
\text { inversion } \\
\text { allele }\end{array}$ \\
\hline Baringo & 15 & $2(13 \%)$ & 0 & $13(87 \%)$ & 87 \\
\hline Tana River & 5 & $1(20 \%)$ & 0 & $4(80 \%)$ & 80 \\
\hline Migori & 25 & 11 (44\%) & $2(8 \%)$ & 12 (48\%) & 52 \\
\hline
\end{tabular}

\section{Association between the 2La chromosomal inversion polymorphism and the knockdown resistance (kdr-east) mutation in An. gambiae}

Considering that the 2La chromosomal inversion has previously been found to be associated with the propensity for mosquitoes to rest indoors at night where a saturation deficit exists, the $2 \mathrm{La}$ inversion was used as a proxy for indoor resting behaviour. Chi-square tests were used to seek association between the 2La inversion karyotype and the $k d r$-east mutation, which was found to occur in significantly higher frequencies than the $k d r$-west mutation in our study populations. There was a significant association between the $k d r$-east mutation and the $2 \mathrm{La}$ inversion (Fisher's exact test statistic value, $F=36.967$, $P=0.000$; Likelihood Ratio $=33.068, P=0.000)$.

\section{Discussion}

This study screened malaria vectors from selected sites in Kenya for the presence of the $k d r$ and ace- $1^{R}$ insecticide resistance markers, and $2 \mathrm{La}$ chromosomal inversion which has been associated with mosquito resting behaviour. It also sought to establish whether there is an association between markers of insecticide resistance and the $2 \mathrm{La}$ inversion and thus infer whether mosquito resting behaviour is associated with insecticide resistance. The study found an absence of the ace- $1^{\mathrm{R}}$ mutation in all the populations studied and a great variation in allele frequencies of $k d r$ and inversion 2La across the sites. An association between the 2La inversion marker and the $k d r$-east mutation marker was observed.
A proper understanding of malaria vector species composition and other dynamics in a population informs the choice of vector control interventions with the greatest likelihood of success. This study reports sympatric occurrence of An. gambiae and An. arabiensis in Migori, Baringo and Tana River counties at varying frequencies, two species that have been described as the most efficient vectors of malaria [22]. Co-existence of several species of a complex in the same environment has previously been reported in many settings $[23,24]$. In Kenya, An. gambiae is known to be common in western region [25-27]. This is reflected in Migori County in the western region where $A n$. gambiae was found to occur in higher frequencies compared to the other study sites. The predominance of An. arabiensis in Kirinyaga and Baringo counties has been observed in previous studies which describe this sibling species as a dominant vector of the Central and Rift valley regions [28-30]. In Kirinyaga, only An. arabiensis was found. It is likely that this species is less affected by pyrethroid treated nets commonly used in the county as it preferentially feeds on cattle and is less endophilic [31, 32]. This gives it a competitive advantage over An. gambiae, which is endophagic, anthropophagic and endophilic in nature and is thus thought to be potentially killed by LLINs [33, 34]. Failure of a small number of the samples to amplify as either of the two sibling species could have been because of poor DNA quality or extremely low DNA concentrations. It is also possible that these samples belonged to other sibling species not targeted by the primers used in molecular identification. To 
ascertain the position, further testing with the relevant primers is necessary.

The 2La inversion is an important component of the natural malaria transmission system as it influences vector resting behaviour and susceptibility to Plasmodium [35]. In their studies for instance, Petrarca and Beier [36] observed that An. gambiae having the standard $2 \mathrm{~L}+{ }^{\mathrm{a}} / 2 \mathrm{~L}+{ }^{\mathrm{a}}$ karyotype were more susceptible to Plasmodium infection compared to those with the inverted 2La/2La homokaryotype. Since mosquitoes bearing the $2 \mathrm{~L}+^{\mathrm{a}}$ arrangement are behaviourally more exophilic, the finding that they are more Plasmodium-susceptible suggests the risk of their forming reservoirs of consistent outdoor malaria transmission. The $2 \mathrm{La}$ inversion has been associated with a higher propensity for indoor resting and a high frequency of this inversion in certain An. gambiae populations would thus mean that vector control applications targeting the indoor space would be more effective against such populations. The arid conditions of Baringo and Tana River seem to favour the occurrence of the $2 \mathrm{La}$ inversion, a situation which has been found to be the case in other studies [17, 22]. The high frequencies of the $2 \mathrm{La}$ inversion in these two regions suggest that most of the An. gambiae mosquitoes in these two regions remain inside human dwellings after blood feeding, consistent with known resting behaviour patterns of this species [37-39]. The implication of this observation is that vector control interventions that target indoor spaces, such as LLINs and IRS would be effective against An. gambiae in these regions. However, the decision on the choice of the intervention would need to be balanced against the fact that An. gambiae constituted only a small proportion of mosquitoes found in the study areas, with the outdoor resting An. arabiensis predominating.

Associations between inversion polymorphisms and insecticide resistance genes have previously been documented whereby loci within the inversion region on the left arm of chromosome 2 were found to be associated with insecticide resistance [39]. Although the $k d r$ mutation is not located within the $2 \mathrm{La}$ inversion region, there is a significant association between the $k d r$-east mutation and the $2 \mathrm{La}$ inversion associated with indoor resting. This suggests that An. gambiae mosquitoes harbouring the $k d r$-east mutation still have a higher propensity to rest indoors suggesting that behavioural resistance may not be an important factor in this study population.

The $k d r v g s c-1014 S$ and $v g s c-1014 F$ alleles were found to occur both in An. gambiae and An. arabiensis. This observation is similar to other studies $[6,40]$ suggesting that both species have received exposure to vector control insecticides that cause selection pressure for knockdown resistance. The variation in frequency of these $k d r$ mutations in An. gambiae and An. arabiensis could be due to environmental and behavioural attributes of these vector species [41]. Some mosquito breeding sites may for example, contain natural xenobiotics which larvae feed on. These compounds have been found to have an impact on the response of mosquitoes to pyrethroids through affecting mosquito metabolism which might also cross-select resistance mechanisms to pyrethroids thus modulating their insecticide tolerance [42, 43]. Outdoor feeding and resting are some behavioural attributes by which a species avoids contact with insecticides [44, 45]. Traits like these eventually influence the development of insecticide resistance and the frequency of $k d r$ and other mutations associated with resistance. While some studies have reported the occurrence of $v g s c-1014 S$ in East Africa only [46, 47] and vgsc-1014F in West Africa only [47], others have reported the co-occurrence of both alleles in these regions $[10,48]$. The $v g s c-1014 F$ allele was first documented in the country in 2012 [6] several years after its first report in West Africa. Other East African countries that have reported occurrence of the vgsc-1014F mutation include Uganda [49], Tanzania [50], Ethiopia [51] and Sudan [52]. Failure of the two mutations to comply with their geographical stratification as previously described indicate major shifts in $k d r$ allele frequencies in malaria endemic countries and suggests gene flow between West Africa and East Africa [47, 53]. Although in the current study the vgsc-1014F mutation occurred at a very low frequency in Migori County, in concordance with previous studies $[6,41,54]$, its presence in East Africa suggests that it is spreading. However, its occurrence remains widespread in West Africa [41].

In this study, we report the presence of the vgsc$1014 S$ allele in Kirinyaga, Central Kenya which was not found in previous studies conducted in the region [55]. Although the allele was found at low frequencies in the current study, there is a possibility that frequencies could increase as a result of insecticide pressure from treated bed nets used as vector control tools in the area [56]. This would have a negative impact on pyrethroid vector control on this site. A possible explanation for the absence of $k d r$ alleles in Tana River is that there is not a high enough buildup of insecticidal pressure to drive resistance genes. Some of the communities living in this region are nomadic pastoralists [57] and it is likely that their temporary house structures do not favor consistent deployment of insecticidal nets $[58,59]$. Furthermore, the additional control methods relied upon such as burning cow dung and herbs to keep mosquitoes off houses have no insecticidal properties. The frequencies of $v g s c-1014 \mathrm{~S}$ in Baringo and Kirinyaga although low present a risk to the continued efficacy of pyrethroid-based vector control interventions. In Migori, the vgsc-1014S allele frequency 
was as high as $65.6 \%$ and is likely attributing to selection pressure by historic intensive pyrethroid spray programmes in the area. Having been classified as a stable malaria endemic county, Migori remained under intense pyrethroid-based IRS from the year 2010 to 2012 supported by the U.S. President Malaria Initiative [60]. Past plus present heavy use of pyrethroid-treated nets that are routinely distributed freely through antenatal and child welfare care clinics and mass campaigns are also likely contributing factors. Frequencies of the $k d r$ mutations are likely to continue increasing and spreading in field mosquito populations as long as pyrethroid insecticide pressure from agricultural pesticides, bed nets and other interventions is present. This is likely to pose a great challenge to the effectiveness of control interventions that employ this insecticide class and others with the same mode of action. To counter this and preserve the efficacy of pyrethroid-based control interventions, there is need for the judicious use of insecticides, such as rotation in time and space of insecticides with different modes of action or their simultaneous use as mixtures [61].

The ace- $1^{R}$ mutation was absent in the study populations. Although this mutation has been reported in several studies in West [41, 62] and Central Africa [63], there are no reports of its existence in Kenya. There is however need for monitoring the presence of this mutation especially in areas where organophosphates and carbamates may be in use for other purposes, such as in agricultural pests control [64]. The potential for this resistance mechanism to rapidly spread in An. gambiae was demonstrated through studies by Djogbénou et al. [62], in which a laboratory strain of An. gambiae homozygous for the ace- $1^{R}$ mutation and code-named AcerKis was developed through introgression of the mutation from the insecticide-resistant An. gambiae (from Bobo-Dioulasso region of Burkina Faso) into the insecticide susceptible $A n$. gambiae Kisumu strain in 2002. The absence of the ace$1^{R}$ allele in this study and the observed moderate phenotypic resistance to organophosphates and carbamates in the country $[65,66]$ may be associated with a metabolic resistance mechanism, such as overexpression of nonspecific esterases (NSE) and elevation of detoxification enzymes.

\section{Conclusion}

The significant association between the $2 \mathrm{La}$ inversion karyotype and $k d r$-east mutation suggests that pyrethroid resistant An. gambiae continue to rest indoors regardless of the presence of treated bed nets and residual sprays, a persistence further substantiated by studies documenting continued mosquito abundance indoors. Behavioural resistance by which Anopheles vectors prefer to not rest indoors may, therefore, not be a factor of concern in our study populations.

\section{Abbreviations}

Ace- ${ }^{R}$ : Resistant acetyl cholinesterase gene; AChE-1: Acetyl cholinesterase-1; Alu l: Arthrobacter luteus restriction enzyme; DNA: Deoxyribonucleic acid; GPIRM: Global Plan for Insecticide Resistance Management; G119S: Guanine to Serine amino acid substitution at locus 119; IR: Insecticide resistance; IRS: Indoor Residual Spraying; ITNs: Insecticide-treated nets; KEMRI: Kenya Medical Research Institute; Kdr: Knockdown resistance; LLINS: Long-Lasting Insecticidal Nets; NMCP: National Malaria Control Program; PCR: Polymerase chain reaction; PMI: President's Malaria Initiative; RFLP: Restriction Fragment Length Polymorphism; s.l.: Sensu lato; s.s.: Sensu stricto; WHO: World Health Organization; Vgsc: Voltage gated sodium channel gene; 2La/a: Inversion arrangement on left arm of chromosome $2 ; 2 \mathrm{~L}+{ }^{\mathrm{a}} /+^{\mathrm{a}}$ : Standard arrangement on left arm of chromosome 2; $2 \mathrm{La} /+\mathrm{a}$ : Heterokaryotype arrangement on left arm of chromosome 2 .

\section{Acknowledgements}

The authors acknowledge help from the Kenya National Malaria Control Programme in field collection of samples used in this study. We also appreciate the Centre for Biotechnology Research and Development, KEMRI, Nairobi and the Centre for Global Health Research, CGHR, Kisumu for providing laboratory space and equipment for molecular analysis.

\section{Disclaimer}

The findings and conclusions in this report are those of the authors and do not necessarily represent the official position of Kenya Medical Research Institute.

\section{Authors' contributions}

LK and CM designed and developed the study. LK also supervised the implementation of the study, assisted in the drafting of the manuscript and reviewed the manuscript. SM carried out laboratory analysis of samples, data analysis and drafted the manuscript. LW, SN, SK and BK assisted in laboratory sample analysis. SR, DM and EO co-supervised the study. All authors read and approved the final manuscript.

\section{Funding}

The research is funded by the Bill and Melinda Gates Foundation through WHO (Award \#54497 awarded to Dr. Charles Mbogo). We are grateful to the Director General, KEMRI for the permission to publish this data.

\section{Availability of data and materials}

The data analysed and used to make conclusions in this study are available from the corresponding author upon request.

\section{Declarations}

Ethics approval and consent to participate

This study was approved by KEMRI Scientific Steering Committee, protocol approval number: KEMRI/SSC/1677.

\section{Consent for publication}

Not applicable.

\section{Competing interests}

The authors declare that they have no competing interests.

\section{Author details}

${ }^{1}$ Department of Biochemistry and Biotechnology, Kenyatta University, P.O Box 43844-00100, Nairobi, Kenya. ${ }^{2}$ Centre for Biotechnology Research and Development, Kenya Medical Research Institute (KEMRI), P.O Box 54840-00200, Nairobi, Kenya. ${ }^{3}$ Institute of Tropical Medicine and Infectious Diseases (ITROMID), P.O. Box 54840-00200, Nairobi, Kenya. ${ }^{4}$ Centre for Global Health Research, KEMRI_CDC, P.O Box 1578-40100, Kisumu, Kenya. ${ }^{5}$ KEMRI -Wellcome Trust Research Programme, Public Health Unit, P.O. Box 43640-00100, Nairobi, Kenya. 
Received: 9 May 2021 Accepted: 28 November 2021

Published online: 13 December 2021

\section{References}

1. WHO. World Malaria Report: 20 years of global progress and challenges. Geneva: World Health Organization; 2020.

2. U.S. President's Malaria Initiative Kenya. Malaria Operational Plan FY 2018 1. 2018;1-95. https://www.pmi.gov/docs/default-source/default-docum ent-library/malaria-operational-plans/fy-2018/fy-2018-kenya-malariaoperational-plan.pdf?sfvrsn $=5$

3. PMI Africa. The PMI Africa IRS (AIRS) Project Indoor Residual Spraying (IRS 2) Task Order Six: AIRS Liberia: entomological monitoring final report2015. www.abtassociates.com. Accessed 19 Jan 2021.

4. Fegan GW, Noor AM, Akhwale WS, Cousens S, Snow RW. Effect of expanded insecticide-treated bednet coverage on child survival in rural Kenya: a longitudinal study. Lancet. 2007;370:1035-9.

5. Hamel MJ, Otieno P, Bayoh N, Kariuki S, Were V, Marwanga D, et al. The combination of indoor residual spraying and insecticide-treated nets provides added protection against malaria compared with insecticidetreated nets alone. Am J Trop Med Hyg. 2011;85:1080-6.

6. Ochomo E, Subramaniam K, Kemei B, Rippon E, Bayoh NM, Kamau L, et al. Presence of the knockdown resistance mutation, Vgsc-1014F in Anopheles gambiae and An. arabiensis in western Kenya. Parasit Vectors. 2015;8:616.

7. Weill M, Malcolm C, Chandre F, Mogensen K, Berthomieu A, Marquine M, et al. The unique mutation in ace-1 giving high insecticide resistance is easily detectable in mosquito vectors. Insect Mol Biol. 2004;13:1-7.

8. Ayala D, Ullastres A, González J. Adaptation through chromosomal inversions in Anopheles. Front Genet. 2014;5:129.

9. Matoke-Muhia D, Gimnig JE, Kamau L, Shililu J, Bayoh MN, Walker ED. Decline in frequency of the 2La chromosomal inversion in Anopheles gambiae (s.s.) in Western Kenya: correlation with increase in ownership of insecticide-treated bed nets. Parasit Vectors. 2016;9:334.

10. Ondeto BM, Nyundo C, Kamau L, Muriu SM, Mwangangi JM, Njagi K, et al. Current status of insecticide resistance among malaria vectors in Kenya. Parasit Vectors. 2017;10:429.

11. Snow RW, Kibuchi E, Karuri SW, Sang G, Gitonga CW, Mwandawiro C, et al. Changing malaria prevalence on the Kenyan coast since 1974: climate, drugs and vector control. PLOS ONE. 2015;10:e0128792.

12. Trape JF, Tall A, Diagne N, Ndiath O, Ly AB, Faye J, et al. Malaria morbidity and pyrethroid resistance after the introduction of insecticide-treated bednets and artemisinin-based combination therapies: a longitudinal study. Lancet Infect Dis. 2011;11:925-32.

13. WHO Global Malaria Programme. Global plan for insecticide resistance management in malaria vectors. Executive summary. Geneva: World Health Organization; 2012.

14. Horowitz AR, Denholm I. Impact of insecticide resistance mechanisms on management strategies. In: Ishaaya I, editor. Biochemical sites of insecticide action and resistance. Heidelberg: Springer; 2001. p. 323-38.

15. Ahoua Alou LP, Koffi AA, Adja MA, Tia E, Kouassi PK, Koné M, et al. Distribution of ace-1R and resistance to carbamates and organophosphates in Anopheles gambiae s.s. populations from Côte d'Ivoire. Malar J. 2010;9:167.

16. Fang Y, Shi WQ, Wu JT, Li YY, Xue JB, Zhang Y. Resistance to pyrethroid and organophosphate insecticides, and the geographical distribution and polymorphisms of target-site mutations in voltage-gated sodium channel and acetylcholinesterase 1 genes in Anopheles sinensis populations in Shanghai. China Parasit Vectors. 2019;12:396.

17. Coluzzi M, Sabatini A, Petrarca V, Di Deco MA. Chromosomal differentiation and adaptation to human environments in the Anopheles gambiae complex. Trans R Soc Trop Med Hyg. 1979;73:483-97.

18. Gillies MT, Coetzee M. A Supplement to the Anophelinae of the South of the Sahara (Afrotropical Region). Publ South African Inst Med Res. 1987;55:1-143.

19. Collins FH, Mendez MA, Rasmussen MO, Mehaffey PC, Besansky NJ, Finnerty $V$. A ribosomal RNA gene probe differentiates member species of the Anopheles gambiae complex. Am J Trop Med Hyg. 1987;37:37-41.
20. Scott JA, Brogdon WG, Collins FH. Identification of single specimens of the Anopheles gambiae complex by the polymerase chain reaction. Am J Trop Med Hyg. 1993;49:520-9.

21. White BJ, Santolamazza F, Kamau L, Pombi M, Grushko O, Mouline K, et al. Molecular karyotyping of the 2La inversion in Anopheles gambiae. Am J Trop Med Hyg. 2007;76:334-9.

22. Sinka ME, Bangs MJ, Manguin S, Coetzee M, Mbogo CM, Hemingway J, et al. The dominant Anopheles vectors of human malaria in Africa, Europe and the Middle East: occurrence data, distribution maps and bionomic précis. Parasit Vectors. 2010;3:117.

23. Imbahale SS, Mukabana WR, Orindi B, Githeko AK, Takken W. Variation in malaria transmission dynamics in three different sites in western Kenya. J Trop Med. 2012;2012:912408.

24. Bayoh MN, Mathias DK, Odiere MR, Mutuku FM, Kamau L, Gimnig JE, et al. Anopheles gambiae: historical population decline associated with regional distribution of insecticide-treated bed nets in western Nyanza Province, Kenya. Malar J. 2010;9:62.

25. Wamae PM, Githeko AK, Otieno GO, Kabiru EW, Duombia SO. Early biting of the Anopheles gambiae s.s. and its challenges to vector control using insecticide treated nets in western Kenya highlands. Acta Trop. 2015;150:136-42

26. Okara RM, Sinka ME, Minakawa N, Mbogo CM, Hay SI, Snow RW. Distribution of the main malaria vectors in Kenya. Malar J. 2010;9:69.

27. Mwangangi JM, Mbogo CM, Orindi BO, Muturi EJ, Midega JT, Nzovu $J$, et al. Shifts in malaria vector species composition and transmission dynamics along the Kenyan coast over the past 20 years. Malar J. 2013;12:13.

28. Mwangangi JM, Shililu J, Muturi EJ, Muriu S, Jacob B, Kabiru EW, et al. Anopheles larval abundance and diversity in three rice agro-village complexes Mwea irrigation scheme, central Kenya. Malar J. 2010;9:228.

29. Mala AO, Irungu LW, Shililu JI, Muturi EJ, Mbogo CC, Njagi JK, et al. Dry season ecology of Anopheles gambiae complex mosquitoes at larval habitats in two traditionally semi-arid villages in Baringo, Kenya. Parasit Vectors. 2011;4:25.

30. , Ondiba IM, Oyieke FA, Ochieng AO, Anyona DN, Nyamongo IK, Estambale BBA. Malaria vector species distribution and seasonal population dynamics across varied ecological zones in Baringo County, Kenya. J Mosq Res. 2017;7:174-83.

31. Takken W, Verhulst NO. Host preferences of blood-feeding mosquitoes. Annu Rev Entomol. 2013;58:433-53.

32. Mayagaya VS, Nkwengulila G, Lyimo IN, Kihonda J, Mtambala H, Ngonyani $\mathrm{H}$, et al. The impact of livestock on the abundance, resting behaviour and sporozoite rate of malaria vectors in southern Tanzania. Malar J. 2015;14:17.

33. Day JF. Host-seeking strategies of mosquito disease vectors. J Am Mosq Control Assoc. 2005;21:17-22.

34. Kitau J, Oxborough RM, Tungu PK, Matowo J, Malima RC, Magesa SM, et al. Species shifts in the Anopheles gambiae complex: do LLINs successfully control Anopheles arabiensis? PLoS ONE. 2012;7:e31481.

35. Riehle MM, Bukhari T, Gneme A, Guelbeogo WM, Coulibaly B, Fofana A, et al. The Anopheles gambiae 2La chromosome inversion is associated with susceptibility to Plasmodium falciparum in Africa. eLife. 2017:6:e25813.

36. Petrarca V, Beier JC. Intraspecific chromosomal polymorphism in the Anopheles gambiae complex as a factor affecting malaria transmission in the Kisumu area of Kenya. Am J Trop Med Hyg. 1992;46:229-37.

37. Githeko AK, Service MW, Mbogo CM, Atieli FK. Resting behaviour, ecology and genetics or malaria vectors in large scale agricultural areas of Western Kenya. Parassitologia. 1996;38:481-9.

38. Highton RB, Bryan JH, Boreham PFL, Chandler JA. Studies on the sibling species Anopheles gambiae Giles and Anopheles arabiensis Patton (Diptera: Culicidae) in the Kisumu area, Kenya. Bull Entomol Res. 1979;69:43-53.

39. Brooke BD, Hunt RH, Chandre F, Carnevale P, Coetzee M. Stable chromosomal inversion polymorphisms and insecticide resistance in the malaria vector mosquito Anopheles gambiae (Diptera: Culicidae). J Med Entomol. 2002;39:568-73.

40. Dabiré KR, Diabaté A, Namontougou M, Djogbenou L, Kengne P, Simard F et al. Distribution of insensitive acetylcholinesterase (ace-1R) in Anopheles gambiae s.l. populations from Burkina Faso (West Africa). Trop Med Int Health. 2009;14:396-403. 
41. Stump AD, Atieli FK, Vulule JM, Besansky NJ. Dynamics of the pyrethroid knockdown resistance allele in western Kenyan populations of Anopheles gambiae in response to insecticide-treated bed net trials. Am J Trop Med Hyg. 2004;70:591-6.

42. Nkya TE, Akhouayri I, Kisinza W, David JP. Impact of environment on mosquito response to pyrethroid insecticides: facts, evidences and prospects. Insect Biochem Mol Biol. 2013;43:407-16.

43. Killeen GF, Govella NJ, Lwetoijera DW, Okumu FO. Most outdoor malaria transmission by behaviourally-resistant Anopheles arabiensis is mediated by mosquitoes that have previously been inside houses. Malar J. 2016;15:225.

44. Russell TL, Govella NJ, Azizi S, Drakeley CJ, Kachur SP, Killeen GF. Increased proportions of outdoor feeding among residual malaria vector populations following increased use of insecticide-treated nets in rural Tanzania. Malar J. 2011;10:80.

45. Kawada H, Dida GO, Ohashi K, Komagata O, Kasai S, Tomita T, et al. Multimodal pyrethroid resistance in malaria vectors, Anopheles gambiae s.S., Anopheles arabiensis, and Anopheles funestus s.s. in western Kenya. PLoS ONE. 2011;6:e22574.

46. Matowo J, Kitau J, Kaaya R, Kavishe R, Wright A, Kisinza W, et al. Trends in the selection of insecticide resistance in Anopheles gambiae s.l. mosquitoes in northwest Tanzania during a community randomized trial of longlasting insecticidal nets and indoor residual spraying. Med Vet Entomol. 2015;29:51-9.

47. Santolamazza F, Calzetta M, Etang J, Barrese E, Dia I, Caccone A, et al. Distribution of knock-down resistance mutations in Anopheles gambiae molecular forms in west and west-central Africa. Malar J. 2008;7:74.

48. Dabiré RK, Namountougou M, Diabaté A, Soma DD, Bado J, Toé HK, et al. Distribution and frequency of kdr mutations within Anopheles gambiae s.l. populations and first report of the Ace.1G119S mutation in Anopheles arabiensis from Burkina Faso (West Africa). PLoS ONE. 2014;9:e0101484.

49. Verhaeghen K, Van Bortel W, Roelants P, Backeljau T, Coosemans M. Detection of the East and West African kdr mutation in Anopheles gambiae and Anopheles arabiensis from Uganda using a new assay based on FRET/Melt Curve analysis. Malar J. 2006;5:16.

50. Kabula B, Kisinza W, Tungu P, Ndege C, Batengana B, Kollo D, et al. Cooccurrence and distribution of East (L1014S) and West (L1014F) African knock-down resistance in Anopheles gambiae sensu lato population of Tanzania. Trop Med Int Health. 2014;19:331-41.

51. Yewhalaw D, Van Bortel W, Denis L, Coosemans M, Duchateau L, Speybroeck N. First evidence of high knockdown resistance frequency in Anopheles arabiensis (Diptera: Culicidae) from Ethiopia. Am J Trop Med Hyg. 2010;83:122-5.

52. Nardini L, Christian RN, Coetzer N, Ranson H, Coetzee M, Koekemoer LL. Detoxification enzymes associated with insecticide resistance in laboratory strains of Anopheles arabiensis of different geographic origin. Parasit Vectors. 2012;5:113.

53. Himeidan YES, Chen H, Chandre F, Donnelly MJ, Yan G. Permethrin and DDT resistance in the malaria vector Anopheles arabiensis from eastern Sudan. Am J Trop Med Hyg. 2007;77:1066-8.
54. Kawada H, Futami K, Komagata O, Kasai S, Tomita T, Sonye G, et al. Distribution of a knockdown resistance mutation (L1014S) in Anopheles gambiae s.s. and Anopheles arabiensis in Western and Southern Kenya. PLoS ONE. 2011;6:e0024323.

55. Chen H, Githeko AK, Githure Jl, Mutunga J, Zhou G, Yan G. Monooxygenase levels and knockdown resistance $(k d r)$ allele frequencies in Anopheles gambiae and Anopheles arabiensis in Kenya. J Med Entomol. 2008:45:242-50.

56. Hemming-Schroeder E, Strahl S, Yang E, Nguyen A, Lo E, Zhong D, et al. Emerging pyrethroid resistance among Anopheles arabiensis in Kenya. Am J Trop Med Hyg. 2018;98:704-9.

57. Mutero CM. Health impact assessment of increased irrigation in the Tana River Basin, Kenya. In: The changing face of irrigation in Kenya: opportunities for anticipating changes in Eastern and Southern Africa; Blank HG, Mutero CM, Murray-Rust H, Eds. IWMI, Colombo, 2002.

58. Heggenhougen HK, Hackethal V, Vivek P. The behavioural and social aspects of malaria and its control. WHO. 2003. TDR/STR/SEB/NOL/03.1.

59. Seck MC, Thwing J, Fall FB, Gomis JF, Deme A, Ndiaye YD, et al. Malaria prevalence, prevention and treatment seeking practices among nomadic pastoralists in northern Senegal. Malar J. 2017;16:413.

60. PMI. Project Indoor Residual Spraying (Irs 2) Task Order Six 2017 PMI Airs Kenya. End of Spray Report. 2017.

61. Chouaïbou M, Kouadio FB, Tia E, Djogbenou L. First report of the East African kdr mutation in an Anopheles gambiae mosquito in Côte d'Ivoire. Wellcome Open Res. 2017;2:8.

62. Djogbénou L, Chandre F, Berthomieu A, Dabiré R, Koffi A, Alout H, et al. Evidence of introgression of the ace-1R mutation and of the ace-1 duplication in West African Anopheles gambiae s.s. PLoS One. 2008;3:e2172.

63. Elanga-Ndille E, Nouage L, Ndo C, Binyang A, Assatse T, Nguiffo-Nguete D, et al. The g119s acetylcholinesterase (Ace-1) target site mutation confers carbamate resistance in the major malaria vector anopheles gambiae from cameroon: a challenge for the coming irs implementation. Genes (Basel). 2019;10:790.

64. Taylor MD, Klaine SJ, Carvalho FP, Barcelo D, Everaarts J. Pesticide residues in coastal tropical ecosystems: distribution, fate and effects. London, New York: Taylor \& Francis; 2003, 541.

65. Ngala J, Kamau L, Mireji P, Mburu J, Mbogo C. Insecticide resistance, Host preference and Plasmodium falciparum parasite rates in Anopheles mosquitoes in Mwea and Ahero rice schemes. J Mosq Res. 2015;5:14.

66. Wanjala CL, Kweka EJ. Malaria vectors insecticides resistance in different agroecosystems in Western Kenya. Front Public Health. 2018;6:55.

\section{Publisher's Note}

Springer Nature remains neutral with regard to jurisdictional claims in published maps and institutional affiliations.

\footnotetext{
Ready to submit your research? Choose BMC and benefit from:

- fast, convenient online submission

- thorough peer review by experienced researchers in your field

- rapid publication on acceptance

- support for research data, including large and complex data types

- gold Open Access which fosters wider collaboration and increased citations

- maximum visibility for your research: over 100M website views per year
}

At $\mathrm{BMC}$, research is always in progress.

Learn more biomedcentral.com/submissions 